\title{
Feasibility and implications of the modular construction approach for rapid post-disaster recovery
}

\author{
Pedram GHANNAD', Yong-Cheol LEE², and Jin Ouk $\mathrm{CHOI}^{3}$ \\ ${ }_{1}^{1}$ Ph.D. Student, Bert S. Turner Department of Construction Management, Louisiana State University \\ ${ }^{2}$ Assistant Professor, Bert S. Turner Department of Construction Management, Louisiana State University \\ ${ }^{3}$ Assistant Professor, Department of Civil and Environmental Engineering and Construction, University of Nevada, Las \\ Vegas
}

Submitted January 2020

Revised March 2020

Accepted April 2020

Published August 2020

\section{Corresponding Author \\ Yong-Cheol Lee \\ yclee@lsu.edu}

Bert S. Turner Department of Construction Management, Louisiana State University 3319 Patrick F. Taylor Hall Baton Rouge, LA 70803

\section{DOI}

http://doi.org/10.29173/ijic220 Pages 64-75

ISSN 2563-5034

Distributed under Creative Commons CC-BY-NC-ND 4.0

\section{ABSTRACT}

The adverse social and financial impacts of catastrophic disasters are increasing as population centers grow. In recent years, destroying homes and infrastructures has resulted in a major loss of life and created countless refugees. For example, Hurricane Katrina in August 2005 damaged over 214,700 homes in New Orleans and forced over 800,000 citizens to live outside of their homes due to flooding. After disastrous events, the government agencies have to respond to post-disaster housing issues quickly and efficiently and provide sufficient resources for temporary housing for short-term disaster relief and reconstruction of destroyed and damaged housing for full rehabilitation. Modular construction is a promising solution for improving the process of post-disaster housing reconstruction because of its inherent characteristic of timeefficiency. This study aimed to evaluate the potentials and feasibility of the prefabricated/modular construction approach that can be adapted to facilitate the postdisaster recovery process. An extensive literature review has been carried out to identify the features of modular construction, which can add value to the post-disaster recovery process. To investigate the suitability and practicability of implementing modular construction for post-disaster reconstruction and to identify major barriers of its implementation, a survey has been conducted among Architecture, Engineering, and Construction (AEC) experts who have experience in prefabrication/modularization, and/or involved in post-disaster reconstruction projects. The results of the study indicate that prefabricated/modular construction is a promising approach to improve time-efficiency of post-disaster reconstruction and tackle challenges of current practices by its unique benefits such as reduced demand for on-site labor (overcome local labor pool constraints impacted by the disaster) and resources (overcome the shortage of equipment and materials), shorter schedule (due to concurrent \& non-seasonal), reduced site congestion, and improved labor productivity (due to assembly line-like and controlled environment).

\section{KEYWORDS}

Post-disaster reconstruction, Modular construction, Prefabrication, Modularization, Industrialized construction 


\section{Introduction}

The disaster has been defined and investigated from various perspectives by several authors. Smith et al. [1] defined a disaster as an unexpected natural or humanmade phenomenon which causes a large number of lives and property losses. Forcael et al. [2] claimed that in 2014 there were 373 natural disasters, most of which were weather-related. These disasters caused overall 296,000 lives losses and about 110 million dollars cost for about 208 million people directly or indirectly. Disasters damage not only homes and buildings but also almost city infrastructure. For example, Hurricane Katrina in August 2005 damaged over 214,700 homes in New Orleans and forced over 800,000 citizens to live outside of their homes due to flooding [3].

From the construction management perspective, the urgent challenge after a disastrous event is the rapid recovery of damaged houses and infrastructures. The most critical and time-consuming step of a post-disaster recovery and reconstruction process is promptly providing permanent housing for affected people [4]. As shown in Figure 1, the FEMA predicted that permanent housing needs might take up to five years to be fulfilled from the time of the disaster's impact [5], which can be a very long period for restoration of an average citizen and returning to a normal livelihood [6]. Therefore, time is a pivotal factor in the reconstruction process to minimize further devastating social and economic consequences in affected communities. To explore a new approach to tackling the challenge of time in the post-disaster recovery, this study investigated a modular construction approach for mass reconstruction.

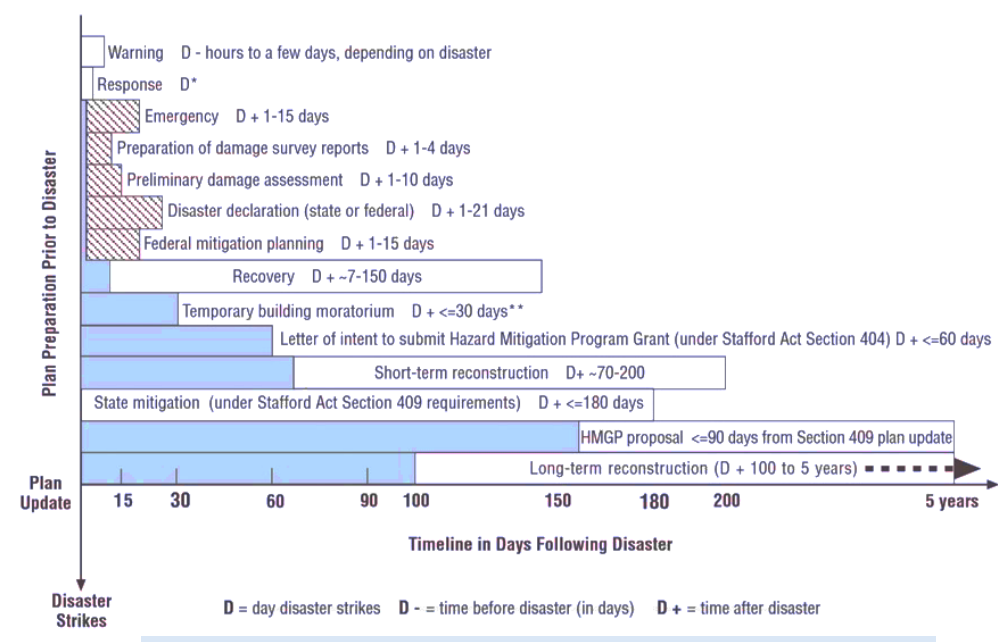

Figure 1. Post-disaster recovery and reconstruction timetable [5]

Prefabricated/modular construction has several potentials to provide a holistic approach to permanent housing reconstruction in disaster-struck areas [7]. Modular construction as a highly time-efficient and holistic approach could solve a number of the common issues of previous post-disaster reconstruction strategies of permanent housing [6]. Time-efficiency is an inherent characteristic of modular construction, which offers great potential for it to be a desirable strategy for post-disaster housing reconstruction. In this paper, the authors investigated the feasibility and perception of modular construction-based post-disaster reconstruction with the survey from industry professionals and identified the competitive features of modular construction for facilitating the disaster recovery process.

According to the Federal Emergency Management Agency (FEMA 2005), disaster management can be categorized into four phases: (1) mitigation, (2) preparedness, (3) response, and (4) recovery. This study focuses on the short-term and long-term recovery phase, which requires an enormous amount of time, funds, and effort after a disaster event.

This paper is organized as follows: first, to achieve the objectives of this study, an extensive and comprehensive literature review was conducted. Second, the literature review results have been validated by subject matter experts who have been involved in relevant projects with a diverse background. Third, based on the extensive literature review findings, an online questionnaire has been designed and distributed among experts. To verify the findings, an analytical comparison has been made between the results of the literature review and the survey by using a descriptive statistical method.

\section{Methodology}

Extensive literature review

A comprehensive literature review has been conducted to identify the major challenges of a post-disaster reconstruction process and current practices. Modular construction also has been investigated by reviewing the literature to find out the features and capabilities that can be leveraged to improve the current status of a postdisaster reconstruction process.

\section{Validation by a survey of subject matter experts}

To validate the findings of our literature review, 18 industry experts were invited to participate in a short survey. The survey contains questions about the feasibility of utilizing modular construction for the reconstruction of the individual building as well as a mass reconstruction of houses with different designs. The invited experts have also been asked to identify the benefits and the barriers of modular construction implementation in the post-disaster recovery process by choosing options from one (1) to four (4), one being strongly disagreed or no importance, and four being strongly agreed or high importance. 
The 18 survey participants are highly qualified as subject matter experts on prefabricated/modular construction and post-disaster reconstruction because they have an average of 20+ years of experience in the AEC/FM industry. 94.4 percent of participants (17 out of 18) have been involved in at least one modular construction in the last five years. Also, 38.9 percent of them ( 7 out of 18) have been involved in a post-disaster reconstruction project using modular construction. Table 1 provides detailed data about the participants' position, work experience, and expertise. The authors also calculated the Cronbach's $\alpha$ (alpha) [8] for testing the consistency of responses. The alpha value is equal to 0.845 , which indicates the "Good" consistency [9] in our responses.

\section{Literature review}

Post-disaster recovery and reconstruction process

This study divides the following two parts of post-disaster reconstruction: housing and infrastructures (e.g., roads, electricity, ports, etc.). Both are the urgent issues, but housing reconstruction after a disaster causing a large number of victims has been mostly addressed in diverse studies. Two types of dwelling have been determined by the terms "shelter" and "housing" [5]. The shelter is temporary accommodation provided until the victims can relocate to permanent houses. On the other hand, "Housing" refers to permanent dwelling with all requirements, including physical, social, and administrative infrastructure [6]. In other words, shelters are provided as the short-term solution of relief process, and permanent houses must be provided in the long run to recover the normal livelihood of the disaster-affected communities.

The post-disaster housing reconstruction process encounters similar challenges to other housing projects in addition to several other challenges due to their special situation. Post-disaster recovery processes for many of the recent disasters have been recorded by the parties involved, and it is worthwhile to examine them. This analysis gives an understanding that critical problems have occurred more commonly and may need an innovative solution. Table 2 presents a summary of several studies focused on the recovery process of previous disastrous events. The table contains information about location, magnitude, and damage caused by disasters as well as information about housing reconstruction after each disaster.

Table 1. Background information of survey participants

\begin{tabular}{|c|c|c|c|c|c|}
\hline & $\begin{array}{l}\text { Company's } \\
\text { Primary Service }\end{array}$ & Position in Company & $\begin{array}{l}\text { Industry } \\
\text { Experience } \\
\text { (Year) }\end{array}$ & $\begin{array}{l}\text { Participation } \\
\text { in MC } \\
\text { Projects }\end{array}$ & $\begin{array}{l}\text { Participation in } \\
\text { Post-Disaster } \\
\text { Reconstruction } \\
\text { Projects }\end{array}$ \\
\hline 1 & $\begin{array}{l}\text { Subcontractor; } \\
\text { Distributor }\end{array}$ & President & 10 & Yes & Yes \\
\hline 2 & Contractor/CM & Branch Operations Leader & 5 & Yes & No \\
\hline 3 & Subcontractor & General Manager & 30 & Yes & Yes \\
\hline 4 & Contractor/CM & Assistant Project Manager & 5 & Yes & No \\
\hline 5 & Contractor/CM & Senior Project Manager & 36 & Yes & No \\
\hline 6 & Contractor/CM & Project Estimator & 7 & Yes & No \\
\hline 7 & Contractor/CM & President & 40 & Yes & No \\
\hline 8 & Contractor/CM & Project Controls Manager & 10 & Yes & No \\
\hline 9 & Contractor/CM & Project Manager & 24 & Yes & No \\
\hline 10 & Contractor/CM & Project Controls Estimator & 17 & Yes & Yes \\
\hline 11 & Contractor/CM & $\begin{array}{l}\text { Vice President Construction } \\
\text { Division }\end{array}$ & 33 & Yes & No \\
\hline 12 & Contractor/CM & Vice President & 25 & Yes & Yes \\
\hline 13 & Contractor/CM & Project Manager & 13 & Yes & No \\
\hline 14 & $\begin{array}{l}\text { Contractor/CM; } \\
\text { Engineering }\end{array}$ & CEO & 30 & Yes & No \\
\hline 15 & Contractor/CM & Vice President & 40 & Yes & Yes \\
\hline 16 & Contractor/CM & Assistant Project Manager & 3 & No & Yes \\
\hline 17 & $\begin{array}{l}\text { Contractor/CM; } \\
\text { Subcontractor }\end{array}$ & $\begin{array}{l}\text { Manager of Business } \\
\text { Development }\end{array}$ & 48 & Yes & Yes \\
\hline 18 & Owner/Developer & Construction Engineering & 3 & Yes & No \\
\hline
\end{tabular}


Table 2. Background details of reviewed previous disastrous events

\begin{tabular}{|c|c|c|c|c|c|c|c|}
\hline Disaster & Source & $\begin{array}{l}\text { Countries } \\
\text { affected }\end{array}$ & Magnitude & Damage caused & $\begin{array}{l}\text { Number of } \\
\text { Houses } \\
\text { reconstructed }\end{array}$ & $\begin{array}{l}\text { Value of } \\
\text { housing } \\
\text { reconstruction }\end{array}$ & $\begin{array}{l}\text { Completion } \\
\text { of the } \\
\text { reconstruction } \\
\text { process }\end{array}$ \\
\hline $\begin{array}{l}\text { Indian Ocean } \\
\text { Tsunami (2004) }\end{array}$ & $\begin{array}{l}\text { Weerakoon } \\
\text { et al. [11] } \\
\text { Koria [12] }\end{array}$ & $\begin{array}{l}\text { Indonesia, } \\
\text { Sri Lanka, } \\
\text { and India }\end{array}$ & $\begin{array}{l}\text { Magnitude } 9.5 \\
\text { earthquake } \\
\text { followed by a } \\
\text { Tsunami }\end{array}$ & $\begin{array}{l}-89,000 \text { houses } \\
\text { heavily damaged } \\
-800,000 \text { people } \\
\text { displaced }\end{array}$ & 60,000 & $\$ 700$ million & $3-5$ years \\
\hline $\begin{array}{l}\text { Kashmir } \\
\text { Earthquake in } \\
\text { Pakistan (2005) }\end{array}$ & $\begin{array}{l}\text { Arshad \& } \\
\text { Athar [13] }\end{array}$ & Pakistan & Magnitude 7.6 & $\begin{array}{l}-3.5 \text { million } \\
\text { people displaced }\end{array}$ & 463,000 & $\begin{array}{l}\$ 1.5 \text { billion } \\
\text { (estimated) }\end{array}$ & $\begin{array}{l}\text { Approximately } \\
5 \text { years }\end{array}$ \\
\hline $\begin{array}{l}\text { Japan Tsunami } \\
\text { (2011) }\end{array}$ & $\begin{array}{l}\text { Structural } \\
\text { Engineers } \\
\text { Association, } \\
\text { Washington } \\
{[15]}\end{array}$ & Japan & $\begin{array}{l}\text { Magnitude } 9.0 \\
\text { earthquake } \\
\text { followed by a } \\
\text { Tsunami }\end{array}$ & $\begin{array}{l}\text {-Over } 100,000 \\
\text { houses heavily } \\
\text { damaged } \\
\text {-More than } \\
300,000 \text { people } \\
\text { displaced }\end{array}$ & - & - & $\begin{array}{l}\text { Continuing } 2.5 \\
\text { years after the } \\
\text { disaster }\end{array}$ \\
\hline
\end{tabular}

According to the previous disasters (presented in Table 2) and the related literature, the challenges of post-disaster housing reconstruction are identified and categorized into seven different areas: (1) Time, (2) Funding, (3) Location (4) Resource and material, (5) Workforce, (6) Planning, Communication, and Coordination, and (7) Resiliency and Sustainability. Table 3 summarizes identified problems during the post-disaster reconstruction process of previous post-disaster recovery processes.

\section{Time-related challenges}

Disaster recovery projects should be completed as quickly as possible to minimize impacts on affected victims [16]. The completion of such projects may take at least five years, which is a considerably long time for the restoration of affected people. Tas et al. [17] stated that 'time' is the most critical factor that determines the postdisaster permanent housing strategy. Besides the reduction in recovery time, time is crucial to reduce construction costs supported by the federal government or personal resources. Weerakoon et al. [11] studied the post-disaster recovery process of the Indian Ocean Tsunami in Sri Lanka. They found that wages of labor and price of the material considerably increased (about 15-25 percent) over the recovery time because of inflation (see Figure 2 (a) and 2 (b)).
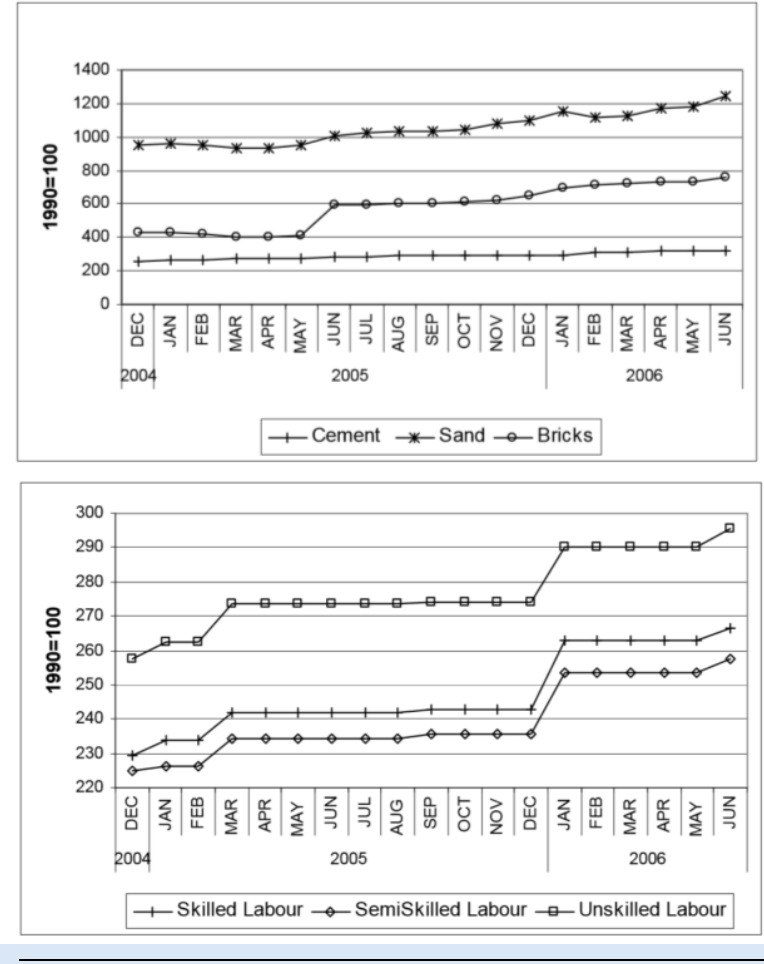

Figure 2. (a). Changes in material price, and (b). Changes in wages for labor during the recovery process (source: Weerakoon et al. [11]) 
Table 3. Identified reconstruction challenges

\begin{tabular}{|c|c|c|c|c|c|c|c|}
\hline Disaster & $\underset{\mathfrak{E}}{\stackrel{\rightleftarrows}{\Xi}}$ & $\underset{\Xi}{\stackrel{D}{\Xi}}$ & 苛 & 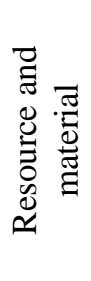 & 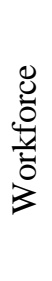 & 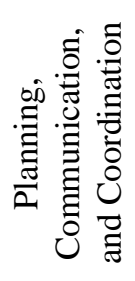 & 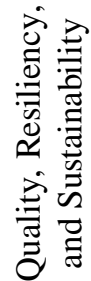 \\
\hline Kocaeli Earthquake & $X$ & $\mathrm{X}$ & $\mathrm{X}$ & & $\mathrm{X}$ & & $X$ \\
\hline Indian Ocean & $\mathrm{X}$ & $\mathrm{X}$ & $\mathrm{X}$ & & $\mathrm{X}$ & $\mathrm{X}$ & \\
\hline Kashmir Earthquake & $\mathrm{X}$ & $\mathrm{X}$ & $\mathrm{X}$ & $\mathrm{X}$ & $\mathrm{X}$ & $\mathrm{X}$ & $\mathrm{X}$ \\
\hline Hurricane Katrina & $\mathrm{X}$ & & $\mathrm{X}$ & $\mathrm{X}$ & $X$ & & \\
\hline Japan Tsunami & $\mathrm{X}$ & $X$ & & & & $X$ & $\mathrm{X}$ \\
\hline
\end{tabular}

\section{Funding-related challenges}

One of the most common problems of the post-disaster recovery process is funding for reconstruction, which can be worsened by deploying inappropriate strategies. Sometimes, spending excessive funds in the relief process, such as building shelters, may cause inadequacy of funds for housing reconstruction projects [18]. The availability of adequate funds is necessary for starting a housing reconstruction process. This fund is mostly from insurance or aids from donors and governments. The challenge of funding is considered as a critical obstacle in a case when the insurance coverage is not available because starting the reconstruction process highly depends on aids from outside [19]. Due to a large number of damages and limited funds, communities affected by a disaster always have difficulties to promptly and adequately initiate their recovery process for reconstruction. The other challenge regarding funding resides in allocating, given funding efficiently and steadily to fulfill the projects' needs, which require wise and systematic portfolio management.

\section{Location-related challenges}

One of the common challenges found at the beginning of the reconstruction, especially after geological disasters such as earthquakes, is finding a location for relocating the affected communities. The substantial damage caused by these disasters makes houses unlivable, and the government agencies must find new locations for temporary or permanent housing. Johnson [20] stated that finding the new location for housing is challenging because the relocate communities should be in convenient distance to jobs and services. Besides, many facilities (e.g., schools, healthcare, shops, etc.) and services (e.g., power, water, transportation, communication, etc.) should be provided for the relocated population to be able to follow their normal pre-disaster livelihood.

\section{Resources and materials challenges}

The other common bottleneck of housing reconstruction projects is the shortage of required resources and construction materials. Housing and infrastructure recovery projects supposed to be simultaneously started by the public and private sections require an enormous amount of construction resources and materials. Since a natural disaster event sweeps out local production facilities and supply systems and causes disruption of transportation systems, it frequently brings serious problems in procuring construction resources in a timely manner during the recovery process [21]. Several studies revealed that the shortage of materials leads to adverse effects on the projects' objectives such as project suspension, quality defects, cost overrun, and delivery delay [22], [23]. Also, Tabmbe et al. [24] stated that during post-earthquake housing reconstruction in the Sikkim Himalaya, many houses construction processes were suspended because the supply of stock material could not fulfill the rising demand.

\section{Workforce-related challenges}

Several case studies revealed that inadequacy of available skilled workforce during construction projects is one of the decisive issues that negatively influence the postdisaster reconstruction projects. The findings of the Koria's study [12] on the reconstruction projects in Sri Lanka indicated that the lack of field staff's relevant experience or training to handle a large and complex project was a key issue in delaying the recovery process. Arshad \& Athar [13] also stated that locals assisting the recovery projects have had a lack of knowledge and/or skills in Pakistan after the 2005 Earthquake. Inadequate worker's skills may lead to poor quality of the constructed facility.

\section{Planning, communication, and coordination}

The other challenges are ineffective coordination and communication among agencies involved in reconstruction. The involvement of federal and local governments, various funding agencies, donors, and other stakeholders requires a comprehensive approach for systematic coordination and extensive knowledge of planning. Roosli et al. [25] identified a lack of expertise 
and knowledge in the relevant authorities acting as a major impediment in the housing reconstruction process.

\section{Quality, resiliency, and sustainability}

The post-disaster period has been recognized as an opportunity to improve quality, resiliency, and sustainability and reduce vulnerability to future disasters [26]. Thus, to establish new facilities and communities, practitioners need to consider their resiliency and sustainability to be prepared for any unexpected future events. Also, several factors must be considered in the post-disaster reconstruction process, including limitation of transportation and accessibility of affected areas.

\section{Modular construction and prefabricated houses}

Modular construction is a modern construction methodology that was introduced as an alternative for traditional on-site (stick-built) construction. In recent years, modular construction has attracted immense attention from many countries because of its inherent superiority of this technology including, but not limited to, construction waste reduction [27], improved quality control, noise and dust reduction [28], higher standards for health and safety [27], [29], and [30], time efficiency [27], [29], and [31], cost savings [32], reduced labor demand [33], and low resource depletion[34]. Choi [35] and Choi et al. [36] provided a comprehensive summary of the advantages and disadvantages of modularization in related literature. The inherent characteristics of modular construction make it the most suitable method for postdisaster housing reconstruction. In the following section, the identified features of modular construction, which can promisingly tackle the mentioned challenges of the postdisaster recovery process, will be analyzed in detail.

\section{Time-efficiency}

One of the most important characteristics of modular construction, which makes it a fitting approach for postdisaster housing reconstruction, is the time-efficiency. According to Lawson et al. [32], it can decrease project completion time by about $50 \%$ in comparison with traditional on-site construction. The flexibility of the modular construction method offers great potential for saving time. All components of a building can be configured as a module together or separately. Shapes and sizes of the modules can vary to comply with the limitations of transportation and technical aspects of construction, such as truck dimensions and height or weight restrictions.

Furthermore, the simultaneous process of mass production and on-site installing of modules will shorten the construction time. Reduction in construction time means that the end-user can use modular houses much sooner than conventional houses. This time saving will benefit the recovery process by not only minimizing the restoration time for affected communities but also avoiding labor and material cost fluctuations.
Long-term cost-benefit ratio

Although it seems that modular construction requires more initial cost and investment, the long-term benefits of this approach are greater in comparison with traditional stick-built construction. Rogan et al. [37] assess the costs and benefits of modular construction as against conventional stick-built construction for a typical fourstory residential building in London. Where the initial investments have only been a mere 2 percent higher for modular construction, but it has received greater benefits from the beginning of the life of the structure. With a 39 percent greater turnover estimated and a 43 percent higher Internal Rate of Return (IRR), modular construction was clearly shown to provide more benefits to the builder as well as the client. Modular construction also has this potential to reduce the material delivery cost, accommodation cost of labors, and on-site usage of equipment such as crane [38].

\section{Resource integration}

Modular construction as technology may not be a complete solution to solve the shortage of resources after a disastrous event. However, it has the potential to reduce the burden of resources demands significantly. Yan et al. [39] categorized the influential factors in resource availability during the post-disaster reconstruction process. Their categorization includes market-related factors, logistics-related factors, project-related factors, organization-related factors, environment-related factors. The impact of logistics-related factors can be considerably reduced by minimizing the number of participants. The study of the reconstruction process after the Kashmir earthquake by Arshad and Athar [13] also confirmed that the fewer number of parties involved in the reconstruction process increases the chance of success. In modular construction, most of the operation is executed by one manufacturing plant. In contrast, in conventional stick-built construction, different resources are ordered and used by various contractors and subcontractors at different times. Also, prototyped and preengineered, and pre-designed products utilized in modular construction can significantly reduce the lead-in time from ordering to delivery of the resources and materials [37]. Considering a large number of houses often required following a natural disaster, suppliers will need to possess the capability to deliver a large number of modules at short notice. However, modular construction would still perform better than traditional stick-built construction in this situation [37].

\section{Reduced demand for labor and resources on-site}

In modular construction, there is minimal work on site to complete the building. As modular construction exports site-based works to off-site, the building project can benefit in two ways. First, on-site labor demand is reduced, which also leads to reduced on-site accommodation costs [38], [40]. Second, resources 
demand on the job site can also be minimized, which helps the fabricator to hire skilled labor in a fabrication shop and the contractor to hire skilled labor on the job site more selectively with lower costs [35].

\section{Pre-planned process}

A high percentage of the construction process of a modular structure is a pre-planned process carried out in a factory environment. External parties would only get involved in the on-site construction. Modular units are generally built with provisions for services. It is only a matter of connecting them on-site once the modules are assembled.

Furthermore, since the interiors, as well as façades, roofs, etc., are all pre-constructed into the modules, the required planning becomes much simpler. Modular construction potentially has the ability to provide a more workable platform for institutions of various disciplines, such as contractors, governmental institutions, non-governmental organizations, and humanitarian agencies, to work together and produce better results; however, this is the desired, not the current practice in the off-site construction industry. Modern integration techniques, such as Building Information Modelling (BIM), can also be applied easily to support the design and planning process of modular construction.

\section{High-quality controlled environment}

Modular construction helps to improve quality control [41]. The production of a housing module is done in a highly controlled environment. The quality checks inside a mass production facility will be more reliable compared to on-site construction, especially in a post-disaster scenario where on-site construction will be under heavy pressure for delivery. This quality control will make sure that the final product suits them with respect to structural stability, livability, and sustainability.

The extensive conducted literature review indicated that modular construction with its inherent characteristics is a promising strategy for rapid post-disaster housing reconstruction. The in-detail analysis of previous case studies also revealed that modular construction brings the potential to improve the post-disaster recovery process and address most of its challenges. Table 4 briefly describes the finding of the literature review. In this table, the authors defined the direct and indirect effects of all identified characteristics of modular construction on different challenges during post-disaster housing reconstruction. The direct effects (presented by D) denotes direct improvements, for example, the timeefficiency of modular construction can directly address the time issue during the recovery process. However, some characteristics of modular construction can indirectly affect the issues during the reconstruction process. For instance, a high-quality controlled environment of prefabricated/modular construction can indirectly tackle the challenge of scarcity of material and resources after disasters by minimizing the wastes and rework. The indirect effects presented by I in Table 4. The table also contains a hypothetical 3-level scale value (Low-Medium-High) for the ability of modular construction to solve each post-disaster reconstruction challenge. According to the critical factors of modular construction-based post-disaster recovery from the literature review section, the authors designed and conducted a survey to collect the industry experts' opinions with the purpose to validate our findings and investigate the feasibility and suitability of modular construction for facilitating post-disaster housing reconstruction.

Table 4. The brief description of the literature review

\begin{tabular}{|c|c|c|c|c|c|c|c|}
\hline & $\stackrel{\mathscr{\Xi}}{\Xi}$ & 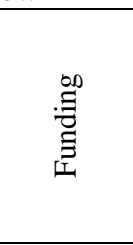 & 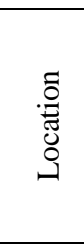 & 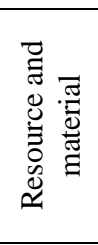 & 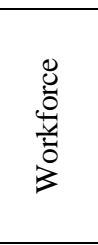 & 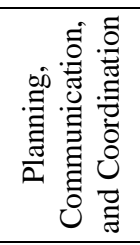 & 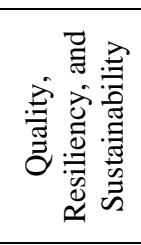 \\
\hline Time-efficiency & $\mathrm{D}$ & I & & & & & \\
\hline Long-term benefits & & $\mathrm{D}$ & & & & & \\
\hline Flexibility & $\mathrm{I}$ & & $\mathrm{I}$ & & & $\mathrm{I}$ & $\mathrm{I}$ \\
\hline Resource integration & $\mathrm{I}$ & & & $\mathrm{I}$ & I & $\mathrm{I}$ & \\
\hline $\begin{array}{l}\text { Reduced demand for labor } \\
\text { and resources on-site }\end{array}$ & & & & & $\mathrm{D}$ & I & \\
\hline Pre-planned process & $\mathrm{I}$ & $\mathrm{I}$ & & & $\mathrm{I}$ & $\mathrm{D}$ & $\mathrm{I}$ \\
\hline $\begin{array}{l}\text { High-quality controlled } \\
\text { environment }\end{array}$ & & & & I & & & $\mathrm{D}$ \\
\hline Ability to solve the issue & High & Medium & Low & Low & High & High & Medium \\
\hline
\end{tabular}

D: Direct effect I: Indirect effect 


\section{Findings of the survey and discussion}

Literature provided several pieces of evidence that implementing modular construction can efficiently address the challenges during the post-disaster housing reconstruction process. The result of the survey also supports the benefits identified in the literature review about the suitability of a modular approach for postdisaster recovery by the average point of 3.16 (out of 4.00) for individual houses and 3.00 for mass construction with different designs. This question has also been added to another survey about modular construction designed and distributed by our collaborators. The results of the survey are also consistent with the literature because over 90 percent of survey participants ( 40 out of 44 ) responded that modular construction/prefabrication could be used for mass post-disaster reconstruction of facilities (average point of 3.23 out of 4). The respondents believed that the process of modular construction is "quicker," and this means "quicker relief." They stated that prefabricators could work in non-affected areas simultaneously with clean-up in affected areas so that they can deliver their products as soon as possible. However, there were few comments from negative respondents. One believed that it could be only a short-term solution. It has also asserted that the amount of preconstruction planning and coordination can impede the quick response to disaster even with modular construction.

Most of the respondents believe that modular construction can reduce the time of post-disaster reconstruction projects, and it received a point of 3.27 , while cost reduction has a lower point (2.88) and consequently lower support among the experts. The experts also evaluated the benefits of modular construction and their influence on making this approach suitable for post-disaster reconstruction. The results have been shown in Table 5 . The average score for each benefit shows its significance, and the standard deviation indicates the level of agreement among participants. The most important characteristics that benefit the post-disaster recovery process are as follows:

- Easier access to required labor and material

- Improved Schedule

- The potential for a quick response

- Better Predictability/Reliability

- Increased Productivity

- Sufficient Labor Supply

These factors are mostly related to the time-efficiency of modular-based construction, minimum requirement of skill and labor, and pre-planning features of modular construction, which reinforce the finding of our literature review. However, the authors expected stronger support for the ability of modular construction in time reduction of post-disaster recovery projects. It indicates that although modular construction can offer the most timeefficient strategy for reconstruction, a construction method is not the only factor that determines the completion time of the projects because of a complex environment and situation after a disaster. The chaotic environment, social and political considerations, and funding limitations are the other factors that can affect the completion time of post-disaster recovery projects.

Table 5. Benefits of modular construction and their importance in its suitability for post-disaster recovery (ranked by score)

\begin{tabular}{|c|l|c|c|c|c|}
\hline$\#$ & Benefits (Ranked by Score) & $\begin{array}{c}\text { Average } \\
\text { Score }\end{array}$ & $\begin{array}{c}\text { Maximum } \\
\text { score }\end{array}$ & $\begin{array}{c}\text { Minimum } \\
\text { Score }\end{array}$ & $\begin{array}{c}\text { Standard } \\
\text { Deviation }\end{array}$ \\
\hline & Easier access to required labor & & & & \\
1 & and material & 0.87 & 1 & 0.3 & 0.2372 \\
\hline 2 & Improved Schedule & 0.87 & 1 & 0.3 & 0.2372 \\
\hline 3 & Potential for quick response & 0.83 & 1 & 0 & 0.3125 \\
\hline 4 & Sufficient Labor Supply & 0.64 & 1 & 0 & 0.2640 \\
\hline 5 & Better Predictability/Reliability & 0.64 & 1 & 0 & 0.2640 \\
\hline 6 & Increased Productivity & 0.63 & 1 & 0 & 0.3691 \\
\hline 7 & Increased Safety & 0.62 & 1 & 0 & 0.3173 \\
\hline & Less required space for job site & & & & \\
8 & in damaged area & 0.56 & 1 & 0 & 0.3867 \\
\hline 9 & Better Quality & 0.54 & 1 & 0 & 0.4203 \\
\hline 10 & Lower Cost & 0.52 & 1 & 0 & 0.3405 \\
\hline 11 & Reduced Weather Impacts & 0.50 & 1 & 0.3 & 0.2587 \\
\hline 12 & Reduced Waste & 0.44 & 1 & 0 & 0.3029 \\
\hline 13 & Reduced Site-based Permits & 0.28 & 0.7 & 0 & 0.3165 \\
\hline 14 & Sustainability & 0.25 & 1 & 0 & 0.2333 \\
\hline 15 & Better Site Operations & 0.22 & 0.7 & 0 & 0.2956 \\
\hline 16 & Less Site Disruption & & & 0.2618 \\
\hline
\end{tabular}


Moreover, it should be noted that in contrast with the literature that indicated modular construction could improve the quality of construction in housing reconstruction projects due to its potential for implementing quality control procedures, the respondent did not identify the high-quality controlled environment of modular construction as an effective factor for improving quality, resiliency, and sustainability of postdisaster reconstruction projects. This conflict might be because of overlooking of quality during the post-disaster reconstruction. The importance of time, pressure from stakeholders for project completion, and high demands are the factors that lead to scarifying the quality to obtain the other objectives of the project. Tabmbe et al. [24] briefly indicated that low-quality of prefabricated houses is one of the shortcomings of this strategy for postdisaster permanent housing reconstruction.

As a part of the survey, participants evaluated the barriers that impede employing modular construction as the main strategy for post-disaster reconstruction (Table 6). The average score for each barrier shows its significance, and the standard deviation indicates the level of agreement among participants. The results show that they identified design and construction culture, quality concerns, and unpredictable conditions after a disaster as the most significant barriers. The design and construction culture barrier for modular construction is not limited to postdisaster reconstruction projects. Gan et al. [42] found that "protectionism" and "conservatism" inherent within the AEC industry culture play a pivotal role in limiting technological innovations such as modular construction. Regarding the quality concerns, it is obvious that the satisfaction of end-users is always a key concern. Although the affected individuals may eventually be thankful for the resettlement of their livelihoods after possibly losing all their possessions, it must be understood that they are entitled to be opinionated of the quality of the finished product. For this reason, institutions such as FEMA [5], APEC [43], and UNDRO [44] have set standards for post-disaster housing reconstruction. However, high demands after a disaster might lead to several deficiencies in module production and undesired defects in the final products. So, more reliable quality control procedures are needed to fulfill most of the requirements.

Table 6. Barriers that impede employing modular construction for post-disaster reconstruction (Ranked by score)

\begin{tabular}{|c|c|c|c|c|c|}
\hline$\#$ & Barriers (Ranked by Score) & $\begin{array}{c}\text { Average } \\
\text { Score }\end{array}$ & $\begin{array}{c}\text { Maximum } \\
\text { score }\end{array}$ & $\begin{array}{c}\text { Minimum } \\
\text { Score }\end{array}$ & $\begin{array}{l}\text { Standard } \\
\text { Deviation }\end{array}$ \\
\hline$\# 1$ & Design+ Construction Culture & 0.67 & 1 & 0.3 & 0.2697 \\
\hline$\# 2$ & $\begin{array}{c}\text { Unpredictable conditions and lack of } \\
\text { ability for planning }\end{array}$ & 0.63 & 1 & 0 & 0.3125 \\
\hline \#3 & $\begin{array}{c}\text { Regulations + Codes + Approval } \\
\text { from Authorities }\end{array}$ & 0.62 & 1 & 0 & 0.3382 \\
\hline \#4 & Distance from Factory to Site & 0.59 & 1 & 0 & 0.3455 \\
\hline$\# 5$ & Owner Tendency & 0.59 & 1 & 0.3 & 0.2645 \\
\hline \#6 & Coordination & 0.56 & 1 & 0 & 0.3534 \\
\hline$\# 7$ & $\begin{array}{l}\text { Program of the Building } \\
\text { Transportation / Logistics }\end{array}$ & 0.56 & 1 & 0 & 0.2975 \\
\hline \#8 & Supply Chain + Procurement & 0.52 & 1 & 0 & 0.3750 \\
\hline$\# 9$ & Cost vs. Value & 0.51 & 1 & 0 & 0.3756 \\
\hline$\# 10$ & Initial Investment & 0.49 & 1 & 0 & 0.3226 \\
\hline$\# 11$ & A/Es Tendency & 0.49 & 1 & 0 & 0.3027 \\
\hline$\# 12$ & $\begin{array}{c}\text { Contractor } \\
\text { Capability/Leadership/Experience }\end{array}$ & 0.47 & 1 & 0 & 0.2803 \\
\hline$\# 13$ & Industry Knowledge & 0.46 & 1 & 0 & 0.3202 \\
\hline \#14 & Design Freeze & 0.46 & 1 & 0 & 0.2549 \\
\hline \#15 & Concern for Quality & 0.44 & 1 & 0 & 0.3534 \\
\hline$\# 16$ & Labor Union & 0.44 & 1 & 0 & 0.3867 \\
\hline \#17 & $\begin{array}{l}\text { Urban Site (Site access and on-site } \\
\text { storage area) }\end{array}$ & 0.43 & 1 & 0 & 0.3343 \\
\hline \#18 & $\begin{array}{c}\text { Fabricator } \\
\text { Capability/Leadership/Experience }\end{array}$ & 0.39 & 1 & 0 & 0.2324 \\
\hline$\# 19$ & Manufacturing Technology & 0.37 & 1 & 0 & 0.2947 \\
\hline$\# 20$ & Site Operations & 0.36 & 1 & 0 & 0.2893 \\
\hline
\end{tabular}




\section{Conclusion}

Rapid and structured post-disaster recovery has been a critical concern in our society. To explore possible solutions for this crucial issue, the authors investigated the modular construction approach through the extensive literature review and surveying the experts. This paper aims to contribute to the body of knowledge that envisions the capabilities of the modular construction technology to support the post-disaster reconstruction of houses continuously. Second, and more importantly, this study investigates the stakeholders' perspectives (including distributors, contractors, and designers) about the benefits and the given barriers of the implication of modular construction-based post-disaster housing construction. In this study, the authors surveyed practitioners who were actively involved in modular construction projects, post-disaster reconstruction projects, or both, which allowed the authors to validate their findings from literature and valuable studies conducted by other scholars.

In this study, it is observed that time is a critical factor in the reconstruction of permanent housing for disaster victims, and it should be minimized for the restoration of affected communities.

Besides, publications and relevant experts in industries clearly indicated that modular construction has a considerable potential to improve this time gap drastically. The shorter construction duration, which is a pivotal characteristic of modular construction, makes this form of construction an excellent solution for providing more rapid permanent houses. Factors such as scarcity of resources, deficiencies in transportation, funding, etc. can still have a detrimental effect on the efficiency of modular construction. However, such factors can be expected in a post-disaster scenario and must be planned. A significant advantage of using modular structures as a post-disaster housing solution is that much of the expertise in reconstruction is directed to one solution provider. This feature makes stakeholders able to address common challenges of the post-disaster reconstruction process, lack of skilled workforce, and inefficiencies in planning, communication, and coordination.

However, several challenges hinder the implementation of prefabricated/modular construction as the mainstream approach for post-disaster reconstruction. In the demanding situation after a disastrous event, numerous stakeholders are involved in the reconstruction process, which makes the decision-making, coordination, and collaboration difficult. Also, due to multiple funding sources and different standards and regulations, it is challenging to integrate the reconstruction process and implement modular construction as a holistic approach. This fact leads to the occasional use of modular construction that practically would fail to leverage all its benefits for rapid post-disaster recovery. Also, owners' lack of knowledge about the costs, benefits, risks of modular construction, and construction/design culture among AEC practitioners are the other challenges of using prefabricated/modular construction for postdisaster. Developing well-established manuals, guidelines, design codes, and regulations can solve the mentioned issue, and change owners' preference to prefabricated/modular housing after disasters.

\section{References}

[1] Smith, K.R., Woodward, A., Campbell-Lendrum, D., Chadee, D.D. Honda, Y., Liu, Q., Olwoch, J.M., Revich, B., and Sauerborn, R. (2014). "Human health: impacts, adaptation, and co-benefits." Climate Change 2014: Impacts, Adaptation, and Vulnerability. Part A: Global and Sectoral Aspects. Contribution of Working Group II to the Fifth Assessment Report of the Intergovernmental Panel on Climate Change. Cambridge University Press, Cambridge, UK and New York, NY, USA, 709-754.

[2] Forcael, E., González, V., Orozco, F., Vargas, S., Pantoja, A., and Moscoso, P. (2014). "Ant colony optimization model for tsunamis evacuation routes." Computer-Aided Civil and Infrastructure Engineering, 29(10), 723-737. https://doi.org/10.1111/mice.12113

[3] US Census Bureau. (2011). "Census bureau releases first detailed data on Katrina damage to New Orleans area housing."

https://www.census.gov/newsroom/releases/archives/ho using/cb11-

28.html?sec_ak_reference $=18.3 \mathrm{c} 0 \mathrm{fd} 717.1498345291 .1 \mathrm{c}$ d608b4 (Accessed Jan., 2020)

[4] Ghannad, P. and Lee, Y.-C. (2020). "Prioritization of post-disaster reconstruction of transportation network using an integrated AHP and genetic algorithm." Accepted (Sep., 2019) for publication in Proceedings, Construction Research Congress, Tempe, AZ, USA, Mar. $8-10$.

[5] FEMA. (2005). Planning for Post Disaster Recovery and Reconstruction. FEMA (Federal Emergency Management Agency), Washington D.C., USA.

[6] Gunawardena, T., Tuan, N., Mendis, P., Aye, L., \& Crawford, R. (2014). "Time-efficient post-disaster housing reconstruction with prefabricated modular structures." Open House International, 39(3), 59-69.

[7] Ghannad, P., Lee, Y. C., \& Choi, J. O. (2019). "Investigating stakeholders' perceptions of feasibility and implications of modular construction-based post-disaster reconstruction." Proceedings, 2019 Modular and Offsite Construction Summit, Banff, AB, Canada, May 21-24, pp. 504-513. https://doi.org/10.29173/mocs132

[8] Cronbach, L. J. (1951). "Coefficient alpha and the internal structure of tests." Psychometrika, 16(3), 297334. https://doi.org/10.1007/BF02310555 
[9] Cortina, J. M. (1993). "What is coefficient alpha? An examination of theory and applications." Journal of Applied Psychology, 78(1), 98. https://doi.org/10.1037/0021-9010.78.1.98

[10] Tas, N., Tas, M., and Cosgun, N. (2011). "Permanent housing production process after 17 August 1999 Marmara Earthquake in Turkey." International Journal of Strategic Property Management, 15(3), 312-328. https://doi.org/10.3846/1648715X.2011.617863

[11] Weerakoon, D., Jayasuriya, S., Arunatilake, N., and Steele, P. (2007). Economic challenges of post-tsunami reconstruction in Sri Lanka (No. 75). Asian Development Bank Institute, Tokyo. http://www.adbi.org/discussionpaper/2007/08/31/2354.sr i.lanka.post.tsunami.reconstruction/ (Accessed Jan., 2020)

[12] Koria, M. (2009). "Managing for innovation in large and complex recovery programmes: Tsunami lessons from Sri Lanka." International Journal of Project Management, 27(2).

https://doi.org/10.1016/j.ijproman.2008.09.005

[13] Arshad, S., \& Athar, S. (2013). Rural housing reconstruction program post-2005 earthquake: Learning from the Pakistan Experience: A manual for post-disaster housing program managers. World Bank Group, Washington, D.C., USA.

[14] Green, R., Bates, L. K., and Smyth, A. (2007). "Impediments to recovery in New Orleans' Upper and Lower Ninth Ward: One year after Hurricane Katrina." Disasters, 31(4), 311-335. https://doi.org/10.1111/j.1467-7717.2007.01011.x

[15] SEAW (Structural Engineers Association, Washington) (2011). Great East Japan (Tohoku) Earthquake and Tsunami. The Japan Journal, 2011 Reconnaissance Observations.

[16] Ghannad, P., Lee, Y. C., Friedland, C., and Yang, E. (2019). "Optimizing the socioeconomic benefit of postdisaster strategies by prioritizing reconstruction of damaged facilities." Proceedings, Computing in Civil Engineering 2019: Smart Cities, Sustainability, and Resilience, Atlanta, Georgia, June 17-19, pp. 180-187. https://doi.org/10.1061/9780784482445.023

[17] Tas, M., Tas, N., and Cosgun, N. (2010). "Study on permanent housing production after 1999 earthquake in Kocaeli (Turkey)." Disaster Prevention and Management: An International Journal, 19(1), 6-19. https://doi.org/10.1108/09653561011022108

[18] Lloyd-Jones, T. (2006). "Mind the Gap! Postdisaster reconstruction and the transition from humanitarian relief." Royal Institute of Chartered Surveyors (RICS). https://www.preventionweb.net/go/9080 (Accessed Jan., 2020)
[19] Hidayat, B., and Egbu, C. O. (2010). "A literature review of the role of project management in post-disaster reconstruction." Proceedings, 26th Annual Association of Researchers in Construction Management (ARCOM) Conference, Leeds, UK, Sept. 6-8, pp. 1269-1278. https://www.tib.eu/de/suchen/id/BLCP\%3ACN0773574 $\underline{08}$

[20] Johnson, C. (2007). "Strategic planning for postdisaster temporary housing." Disasters, 31(4), 435-459. https://doi.org/10.1111/j.1467-7717.2007.01018.x

[21] Chang, Y., Wilkinson, S., Potangaroa, R., \& Seville, E. (2010). "Resourcing challenges for post-disaster housing reconstruction: a comparative analysis." Building Research \& Information, 38(3), 247-264. https://doi.org/10.1080/09613211003693945

[22] Boen, T. (2006). "Building a safer Aceh, reconstruction of houses, one year after the Dec. 26, 2004 tsunami." Presented at the 40th Anniversary of Trisakti University, "Answering the Challenges in Today's Civil Engineering”, Jan. 26, 2006.

[23] Steinberg, F. (2007). "Housing reconstruction and rehabilitation in Aceh and Nias, Indonesia-Rebuilding lives." Habitat International, 31(1), 150-166. https://doi.org/10.1016/j.habitatint.2006.11.002

[24] Tambe, S., Pradhan, S., Donka, P., \& Singh, P. (2018). "Post-earthquake housing reconstruction in the Sikkim Himalaya: Approaches, challenges, and lessons learnt." Development in Practice, 28(5), 647-660. https://doi.org/10.1080/09614524.2018.1469601

[25] Roosli, R., Vebry, M., Othuman Mydin, M. A., \& Ismail, M. (2012). "Building and planning of postdisaster rehabilitation and reconstruction." International Journal of Academic Research, 4(1).

[26] Davidson, C. H., Johnson, C., Lizarralde, G., Dikmen, N., and Sliwinski, A. (2007). "Truths and myths about community participation in post-disaster housing projects." Habitat International, 31(1), 100-115. https://doi.org/10.1016/j.habitatint.2006.08.003

[27] Modular Building Institute (2010). Improving Construction Efficiency \& Productivity with Modular Construction. Modular Building Institute, Charlottesville, VA, USA.

[28] Pons, O., and Wadel, G. (2011). "Environmental impacts of prefabricated school buildings in Catalonia." Habitat International, 35(4), 553-563. https://doi.org/10.1016/j.habitatint.2011.03.005

[29] CII (2002). Implementing the prefabrication, preassembly, modularization, and offsite fabrication decision framework: Guide and tool. Construction Industry Institute, Austin, TX. 
[30] CII (2012). Industrial modularization: How to optimize; How to maximize. The University of Texas at Austin, Construction Industry Institute, Austin, TX, USA.

[31] CII (1987). Constructability improvement using prefabrication, preassembly, and modularization. The University of Texas at Austin, Construction Industry Institute, Austin, TX, USA.

[32] Lawson, R. M., Ogden, R. G., and Bergin, R. (2011). "Application of modular construction in high-rise buildings." Journal of Architectural Engineering, 18(2), 148-154. https://doi.org/10.1061/(ASCE)AE.1943$\underline{5568.0000057}$

[33] Nadim, W., and Goulding, J. S. (2010). “Offsite production in the UK: the way forward? A UK construction industry perspective." Construction Innovation, 10(2), 181-202. http://dx.doi.org/10.1108/14714171011037183

[34] Won, I., Na, Y., Kim, J. T., and Kim, S. (2013). "Energy-efficient algorithms of the steam curing for the in situ production of precast concrete members." Energy and Buildings, 64, 275-284. https://doi.org/10.1016/j.enbuild.2013.05.019

[35] Choi, J. O. (2014). Links between modularization critical success factors and project performance. Doctoral dissertation, The University of Texas at Austin, UT Electronic These and Dissertations, Department of Civil, Architectural, and Environmental Engineering. http://hdl.handle.net/2152/25030

[36] Choi, J., Chen, X., and Kim, T. (2017). "Opportunities and challenges of modular methods in dense urban environment." International Journal of Construction Management, 19(2), 93-105. https://doi.org/10.1080/15623599.2017.1382093

[37] Rogan, A. L., Lawson, R. M., and Bates-Brkljac, N. (2000). Value and benefits assessment of modular construction. Steel Construction Institute, Ascot, UK.

[38] Fagerlund, W. R. (2001). Decision framework for prefabrication, pre-assembly and modularization in industrial construction. Doctoral dissertation, University of Texas at Austin.

[39] Yan, C. et al. (2011). "Identifying factors affecting resource availability for post-disaster reconstruction: A case study in China". Construction Management and Economics, 29(1), $37-48$.

https://doi.org/10.1080/01446193.2010.521761

[40] Gotlieb, J., Stringfellow, T., and Rice, R. (2001). "Power plant design taking full advantage of modularization." Power Engineering, 6(105). https://www.power-eng.com/2001/06/01/power-plantdesign-taking-full-advantage-of-modularization/

[41] Lapp, C. W., and Golay, M. W. (1997). "Modular design and construction techniques for nuclear power plants." Nuclear Engineering and Design, 172(3), 327349.

[42] Gan, X., Chang, R., Zuo, J., Wen, T., and Zillante, G. (2018). "Barriers to the transition towards off-site construction in China: An interpretive structural modeling approach." Journal of Cleaner Production, 197, 8-18. https://doi.org/10.1016/j.jclepro.2018.06.184

[43] APEC (Asia Pacific Economic Cooperation) (2009). Guidelines and best practices for post-disaster damage and loss assessment; Report from APEC workshop on damage assessment techniques. APEC Emergency Preparedness Working Group in Asia, Hong Kong.

[44] Office of the United Nations Disaster Relief Coordinator (1979). Natural disasters and vulnerability analysis. UNDRO (United Nations Disaster Relief Organization), Geneva, $\mathrm{CH}$. 